\title{
An Evaluation of Third-Party Mobile Payment Usage Intention in China
}

\author{
X.M. Lv, C.C. Su, Z.Y. Huang, T.K. Gu \\ School of Computer Science and Information Engineering \\ Zhejiang Gongshang University \\ China
}

\begin{abstract}
This paper analyses the current situation of Chinese mobile payment industry, and then discusses the win-win benefit mode that take third-party mobile payment companies as main body. Now, two kinds of payment processes - the web page payment and the APP payment is summarized, meanwhile, the paper explores five kinds of major characteristics of this win-win commerce mode. Our dataset is collected by online questionnaires and field research focusing on the usage intention of mobile payment services. Moreover, we put forward an index system to describe the level of usage intention, next to do Principal Component Analysis (PCA) and base on it to establish an evaluation model. Finally, we prove that this model could correctly describe the usage intention of users.
\end{abstract}

Keywords-third-party mobile payment; PCA; usage intention; alipay; mobile e-commerce

\section{INTRODUCTION}

With the rapid and widespread development of communication technology, information technology and Internet, electronic payment is no longer a strange item. For young generation, electronic banking is no longer an emerg ing banking business, instead, it has become a kind of traditional banking business. Meanwhile, mobile payment given birth by mobile e-commerce and s mart technology becomes a direction of electronic banking business gradually and brings about a profound revolution to individual financial system [1].

For one thing, this article analyses the existing third-party mobile payment's business pattern and payment processes theoretically, and investigates the present status of mobile payment in some parts of China. For another, we collect relevant data by field and network investigation, and then do some data analysis on the utilization of the group's mobile payment based on it.

\section{MOBILE PAYMENTS}

\section{A. Definition}

Mobile Payment possess has two definitions [2] that represent different range of meanings. Broadly speaking, it means a process that both sides of a deal exchange financial value through mobile devices for so me products or services. In a narrow sense, its transfer and payment, based on the wireless communication technology, in a non-voice mode way, are implemented by the mobile phone terminal.

NFC [3] payment refers that consumers pay to the merchant immediately by phone when they purchase goods or services, and payment process is going on the spot through the
NFC, infrared or Bluetooth channel to achieve local communication with vending machines or POS machines. The larger-range payment_remote payment means the mobile terminal interact with the backend server through a wireless communication network, to finish payment transaction processing by the server-side. Cu rrently, the mainstream of the mobile payment are near field communication [4] and pose terminal swipe function using smartphone through an external card reader which is originated in the square company.

\section{B. Mobile Payments and Mobile Commerce in China}

Mobile e-commerce as an important part of e-commerce develops rapidly and so increases mobile e-payment market demand in recent years in China. Driven by policy and market, mobile payment industry actively pilots the mobile payment application and accelerates market expansion. China Electronic Commerce Research Centre (100EC.CN) monitoring data shows [5], up to December 2013, China Mobile e-commerce market has reached 232.5 billion Yuan, an increase of $141 \%$, still maintains rapid growth trend.

Chinese booming mobile e-commerce gives payment companies a great opportunity for development, Alibaba is a typical example. Alibaba's payment product - Alipay accumulatively reaches over 900 -billion - Yuan transactions in mobile terminal payment has made it become the largest mobile payment company in the world in 2013 [6]. Mobile Terminal (MT) Alipay contains the PC Alipay's functions (transfer and payment), also due to the characteristics of the mobile phone, it contains more innovative services, such as "personally pay", "dimensional code to pay" and others, you can also add services to Alipay, which make it become your own pers onalized mobile.

\section{Third-Party Mobile Payment Business Pattern}

Mobile payment involves complex industry value chain, there must be innovative business patterns plus continuous testing and revision during implementation. Establishing business pattern which satisfies interests of all parties is a fundamental guarantee to effectively promote the development of mobile payments market. Mobile payment company as a third-party economic entity is independent from banks and mobile carriers, owns independent operation rights, platform operators, acting as a bridge and link, connect users, businesses, banks and are responsible for bank accounts' funds transfer and settlement between the users and the merchants. 


\section{Payment Service Benefit Pattern}

Third-party Payment Company is the heart of the industry chain as a separate economic entity, merchants and banks are just its partners, fig. 1. Third-party payment service provider's benefit mainly from 3 parts: 1) Provide credit data, the data can be sold to the large institutions; 2) Share users' consumption share with third-party company by a certain percentage with Merchants and banks; 3) Product recommendations which is based on consumers' behaviour data.

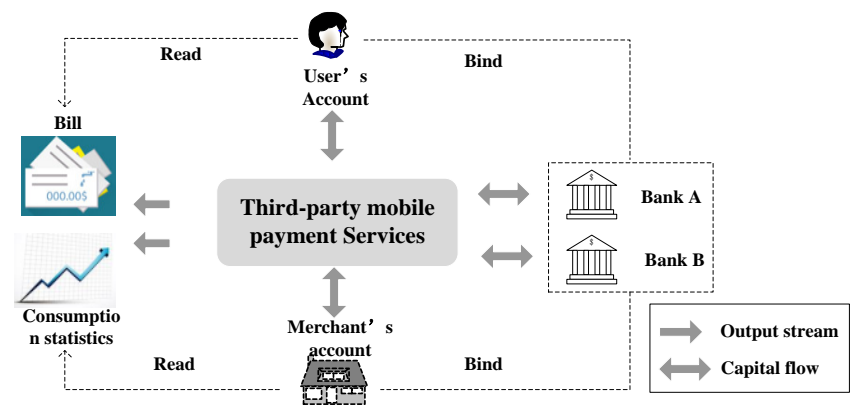

FIGURE I. PATTERN OF PAYMENT SERVICE OPERAT ING

\section{E. Two Kinds of Third-Party Payment Processes}

Transaction process through third-party mobile payment APP has incomparable advantages, its simple steps, no capital distribution costs, the purchase of needed goods anywhere, which make third-party payment APP more and more popular for consumers. The early mobile payment APP lacks advanced payment technology, developers tended to design complex payment processes in order to improve the security of transactions, This behaviour that sacrifices simplicity of the payment process to improve transaction security will reduce users' consumption experience, but now with payment technology maturing, Two kinds of payment processes which not only ensure the security of transactions but also improve the efficiency of the payment are designed:

1) Third-Party Mobile Payment Website: It assumes that consumers have installed plugin of third-party payment APP in the phone. When the network is unimpeded, through a browser or APP client, users can login in virtual mall to buy favourite products. Further, after users conform product list and fill out receiving address, system turns into order-made page, the system provides two kinds of pay ment_—web page or APP for users to choose, if page, users' mobile phone will accept and recognize a digital authentication code sent by third-party payment system, if authentication code is correctly identified, it returns that payment is successful otherwise is failed, fig. 2, Pay ment on the website just one step to complete the verification process which is often used in micro-payment because of its convenience.

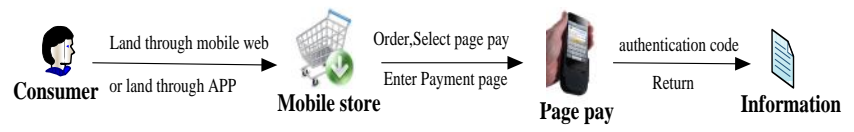

FIGURE II. PAY THROUGH THE MOBILE WEBSITE.
2) Third-Party Payment APP Payment: Differently, thirdparty payment APP must be installed on the user's mobile phone, mobile store page jumps to APP login screen after users finish orders, and then users enter login password and payment password for pay fig. 3. APP payment process would take twice password verification, however, because of its highsecurity advantage, in more situations it will be used for large transaction.

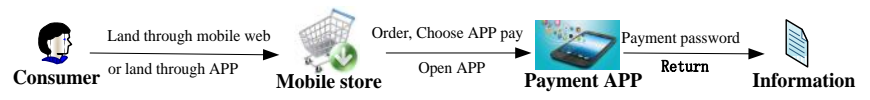

FIGURE III.PAYTHROUGH THEPAYMENT APP.

\section{F. Characteristics of the Business Pattern}

A third-party mobile payment company as main body mainly has the following characteristics: 1) A clear division of labour; and responsibility distribution among banks, merchants, third-party mobile payment companies and consumers; 2) Third-party mobile payment company plays a "interposer" role, simplifies the complex relationship among banks, merchants, users and other interest groups from the many- to -many relationship to many- to -one relationship, and so greatly improves the efficiency of business operation; 3) Provide a platform for merchants to advertise; 4) Users just adding to the platform can achieve cross-bank payment transactions, and have more rights to choose freely; 5) third-party mobile payment company needs high ability such as high appeal and awareness of the industry in marketing, technical R \& D, fund operation and so on.

Third-party payment service providers can coordinate relationship among banks, users and commercial tenant, however, since there is a lack of payment providers in terms of business innovation market responsiveness, capital operation ability and overall coordination, etc. power of third-party is not enough to control the development of industrial chain.

\section{EVALUAT ION OF THIRD-PARTY PAYMENT USAGE INTENTION}

\section{A. Source of Data}

We investigate usage intention of mobile pay ment within a certain range of China. The sample data is mainly collected from Hangzhou, Yiwu, Dongyang, Yuyao, and Xiaosha. In order to diversify sample structure, we put in questionnaires on the network, a total of 158 valid samples being collected.

\section{B. Mathematical Description of the Evaluation Model}

When creating evaluation model of third-party payment's usage intention, we adopted two primary indexes - public praise and user experience, coupled with the risk, practicality, portability, popularity, recommendation degree 5 secondary indexes to construct evaluation model, as shown in table. 1. The initial evaluation model is described as the follow:

$$
\text { Total }=a_{1} x_{1}+a_{3} x_{3}+a_{4} x_{4}+a_{2} x_{2}+a_{5} x_{5}+b
$$

Total means the evaluation score of users' usage intention, $\left(a_{1} x_{1}+a_{3} x_{3}+a_{4} x_{4}\right)$ means public praise score, $\left(a_{2} x_{2}+a_{5} x_{5}\right)$ means user experience score, $b$ is a constant term, 
$x_{1}$-Risk, $\quad x_{2}$-popularity, $x_{3}$-convenience, $x_{4}$ Practicality, $x_{5}$ - Recommendation.

TABLE I. THE INDEX SYST EM OF USERS' USAGE INTENTION.

\begin{tabular}{cccl}
\hline \multirow{2}{*}{$\begin{array}{c}\text { Target } \\
\text { layer }\end{array}$} & $\begin{array}{c}\text { Primary } \\
\text { indexs }\end{array}$ & Secondary indexs & \multicolumn{1}{c}{ Interpretation } \\
\hline & \multirow{2}{*}{$\begin{array}{c}\text { Usage } \\
\text { intention }\end{array}$} & Recommendation & $\begin{array}{l}\text { Friends would recommend payment mobile } \\
\text { payment APP or payment functions to each other }\end{array}$ \\
\cline { 3 - 4 } & \multirow{2}{*}{$\begin{array}{c}\text { User } \\
\text { experience }\end{array}$} & Popularity & $\begin{array}{l}\text { People around have installed and Used mobile } \\
\text { payment services }\end{array}$ \\
\cline { 3 - 4 } & & Practicality & $\begin{array}{l}\text { Mobile payment services can be used anytime, } \\
\text { anywhere, simple operation }\end{array}$ \\
\cline { 3 - 4 } & Risk & $\begin{array}{l}\text { Trust its security, mobile payment services will } \\
\text { not leak users' information }\end{array}$ \\
\hline
\end{tabular}

\section{Evaluation Modelling}

Adopt PCA method. KMO and Bartlett's test shows that $\mathrm{KMO}$ test coefficient is 0.791 , so PCA is suitable. At the same time, Bartlett's test : $0.000<0.05$, so reject the null hypothesis, relationship matrix of these 5 variables will not be considered the unit matrix, that is to say, there is a relationship between these five variables, for another, the corresponding eigenvector $\mathrm{A}$ is known: $\mathrm{A}=(2.553,0.823,0.646,0.513,0.466)$, Fig. 4.

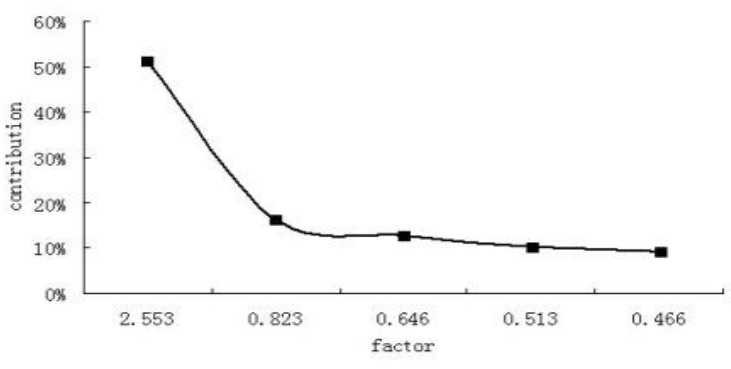

FIGURE IV. CONT RIBUTION CHART.

Since the principal component contribution of the first three variables reach more than $80 \%$ (principal component contribution is shown in chart, the number of independent variables can be simplified to 3 , so the evaluation model will be changed into:

$$
\text { Total }=c_{1} y_{1}+c_{2} y_{2}+c_{3} y_{3}+d
$$

Adopt regression analysis method. To do regression analysis using scores of 3 principal component factors and scores of usage intention (dependent variable), coefficient of determination is 0.842 , shows that the regression model is feasible, and $\mathrm{Sig}=0.000<0.05$, further confirm that the regression model is feasible. Coefficients of formula (2) $c_{1}, c_{2} c_{3}$ can be calculated from the data of regression analysis.

According to table 2, we see the variable ${ }^{y_{3}}$ test coefficient: sig $=0.487>0.05$, so accept the null hypothesis, as a result $c_{3}=0, c_{1}=1.411, c_{2}=0.146, d=7.181$, here is the usage intention evaluation model by PCA and regression analys is :

$$
\text { Totle }=1.411 y_{1}+0.146 y_{2}+7.181
$$

\section{Model Validation}

We collect 53 samples from the same areas which will be used in the model test, and we define that: $\operatorname{dis}=\mid$ Total $-A u \mid$, Total _score of evaluation model, Aui — score of actual usage intention

If dis $\leq 1 \_$is considered to be very consistent;

If $1<$ dis $\leq 2$ _ is considered to be partly consistent;

If dis $>2$ is considered to be inconsistent, Statistical results follow:

According to table 3, we can find that the proportion of very consistence and partly consistence is $96.23 \%$. So we can conclude that the evaluation model we construct is very accurate.

TABLE II. RESULT OF REGRESSION ANALYSIS.

\begin{tabular}{ccccc}
\hline Model & $\begin{array}{c}\text { Unstandardized Standardized } \\
\text { Coefficients }\end{array}$ & Coefficients & T & Sig \\
\hline Constant & 7.181 & & 140.981 & 0 \\
C1 & 1.411 & 0.912 & 27.609 & 0 \\
C2 & 0.146 & 0.095 & 2.865 & 0.005 \\
C3 & -0.036 & -0.023 & -0.696 & 0.487 \\
\hline
\end{tabular}

TABLE III. RESULT OF MODEL VALIDATION.

\begin{tabular}{cccccc}
\hline $\begin{array}{c}\text { evaluation } \\
\text { result type }\end{array}$ & $\begin{array}{c}\text { very } \\
\text { consistent }\end{array}$ & $\begin{array}{c}\text { partly } \\
\text { consistent }\end{array}$ & inconsistent total \\
\hline number of samples & 37 & 14 & 2 & 53 \\
proportion $/ \%$ & 69.81 & 26.42 & 3.77 & 100
\end{tabular}

\section{SUMMARY}

All in all, we extract three public factors from five related variables based on principal component analysis theory and construct an evaluation model by a regression analysis of these variables. Then, we collect 53 samples from the same areas to judge the model's accuracy. Finally, we find the evaluation model is very accurate because the model's validation is over $90 \%$. According to our research above, we can use the evaluation model to help us know user payment usage intention clearly.

\section{ACKNOWLEDGEMENT}

This research is supported by The National Key Technology R\&D Program of China (Grant 2012BAI34B015), Major Project for Science and Technology Plan of Hangzhou (No. 20122511A26), Natural Science Foundation of Zhejiang Province (Grant LY14F020002), This research is supported by the Contemporary Business and Trade Research Center of Zhejiang Gongshang University which is the Key Research Institutes of Social Sciences and Humanities Ministry of Education (Grant 14SMXY04YB). 


\section{REFERENCES}

[1] Jing, L., L. Jia-Le, and J. Huan-Yong, Empirical Study of Influence Fact ors of Adaption Intention of Mobile Payment based on TAM Model in China. Intemational Joumal of $U-$ \& E-Service, Science \& Technology, 7(1), pp. 119-132, 2014.

[2] Gummerus, J. and M. Pihlström, Context and mobile services' value-inuse. Joumal of Retailing \& Consumer Services, 18(6), pp. 521-533, 2011.

[3] Gong, W., et al., Research of NFC Framework in MeeGo Harmattan, in Proceedings of the International Conference on Information Engineering and Applications (IEA) 2012, Z. Zhong, Editor. Springer London, pp. 437-444, 2013.

[4] Wu, Szu-Hui, and Chyan Yang. Technology-NFC-micro SD Technology, 2013.

[5] Dai, Weihui, Xiang Cai, Haifeng Wu, Weidong Zhao, and Xuan Li. "An Integrated Mobile Phone Payment System Based on 3G Network", Journal of Networks, 2011.

[6] Cankaoxiaoxi, http://finance.cankaoxiaoxi.com/2014/0210/345325.shtml 